\title{
CERTIFIED ROOMS FOR ELEARNING STUDENTS EVALUATION
}

\author{
Jorge Borges ${ }^{1}$, Carlos Vaz ${ }^{1}$, Margarida Amaral ${ }^{2}$, \\ Elsa Justino 1, João Barroso 1, 3, Arsénio Reis 1, 3 \\ ${ }^{1}$ Universidade de Trás-os-Montes e Alto Douro (UTAD), Vila real, PORTUGAL \\ ${ }^{2}$ Universidade do Porto, Porto, PORTUGAL \\ ${ }^{3}$ Instituto de Engenharia de Sistemas e Computadores, Tecnologia e Ciência (INESC TEC), \\ Porto, PORTUGAL
}

\begin{abstract}
The University of Trás-os-Montes e Alto Douro is part of a consortium that is providing courses in an e-learning model. In this courses, the students evaluation requires their physical presence. Currently, the consortium has the general objective of provide evaluation activities in all of the consortium's institutions, independently of the student's Higher Education Institution (HEI) of origin. That way, the student can go through the learning process on-line, using the Learning Management System (LMS), and attend an evaluation activity at the HEI geographically more conveniently located. In pursuing this objective, the consortium is creating a set of specific rooms with the sole purpose of supporting the evaluation of e-learning students. These rooms are located in each one of the HEIs, and equipped with thin personal computers (PC), connected to a local, properly configured, server. These PCs and server will run a customized version of the operating system, in a Virtual Desktop Infrastructure (VDI) model, providing a controlled and safe infrastructure for the usage of the LMS to execute the evaluation activities. In a first phase, it is being created one room in each one of the consortium HEls. A set of rules and a certification process will be designed, in order to have a standard level of service across all the rooms. Together with the certification process it will also be defined an audit process in order to regularly verify the compliance of the rooms with the previously designed certification standards.
\end{abstract}

Keywords: Certified Rooms, Online Evaluation, Higher Education Institutions, E-learning

\section{INTRODUCTION}

The Higher Education Institutions (HEI) have researching and teaching as the most important features of their missions. For most institutions, teaching, in particular, is the core of the HEl's activities. The teaching related activities can be clustered in three major groups: class teaching; evaluation; and certification. The nature and execution of this activities hasn't considerably changed over the modern HEl's life cycle. In fact: class teaching is mostly executed on a classroom, in which a professor lectures a group of students, on a pre-determined semester schedule; the student's evaluation, typically, is also executed at the end of the semester in the form of final written exams; and the certification is still provided to students as paper credential documents, certifying their academic achievements.

With the introduction of Information and Communications Technologies (ICT), the HEls have struggled to incorporate this new technology in their business models, particularly, in the teaching related activities, and most have adopted some sort of Learning Management System (LMS) [1][2]. These systems are now widespread and can provide the features to fully support the processes of learning and teaching, as well as the students' evaluation. LMS are used by HEls mostly in e-learning or bleaning models, in which the students have access to the learning contents and some online, subject specific, activities. The evaluation activities are supported by several LMS technological mechanisms in order to assure the quality of the evaluation, regarding the possibility of electronic fraud. From a pedagogical perspective, there are also several mechanisms that professors can use to design the evaluation process in order to prevent specific types of frauds. Both of these mechanisms, technological and pedagogical, have their limitations. So, generally, HEls are still requiring the physical presence of the students for the evaluation actions at the end of the semester.

The University of Trás-os-Montes e Alto Douro (UTAD) is part of a HEls consortium that is providing training classes in an e-learning model, in which the students' evaluation requires the physical presence of the student. The HEl consortium has a general objective of providing evaluation activities in any of the consortium HEls, independently of the students' HEI of origin. That way, the student can 
go through the learning process on-line, using the LMS, and attend the evaluation activities at the HEI geographically more conveniently located. As consequence, this evaluation activities must be designed in order to support the evaluation as designed and provided by the LMS and to assure an evaluation process as reliable as a traditional $\mathrm{HEI}$ on site evaluation [3][4].

To fulfil the objective previously stated, the HEI consortium is creating a set of specific rooms with the sole purpose of supporting the evaluation of e-learning students. These rooms are located in each one of the $\mathrm{HEl}$, and equipped with thin personal computers (PC) connected to a server. These PCs and server will run a customized version of the operating system, in a Virtual Desktop Infrastructure (VDI) model, providing a controlled and safe infrastructure for the usage of the LMS to execute the evaluation activities. To setup an evaluation activity, a professor must create the evaluation activity in his HEl's LMS course and make it available to the evaluation room equipment at the date of the specific evaluation activity.

In a preliminary version of the evaluation rooms, it is being created one room in each one of the consortium $\mathrm{HEl}$, e.g., two rooms with one hundred places and one room with twenty five places. The LMS widely used by the consortium HEI is Moodle [5], which has been adopted as the standard LMS to use in the evaluation rooms, together with the Safe Exam browser [6]. On the current setup, a PC in the evaluation room will load a specific VDI image, according to the student profile. That image includes a single application, the Safe Exam browser, which provides a user interface of a single window with exclusive access to the user's LMS exam.

These rooms and the PCs infrastructure are technically designed to provide an excellent level of service and to minimize the risk of fraud. Their management is locally assured by their owner HEl. The usage of this rooms by third party HEls, besides the owner HEl, is a matter of inter HEls agreements, based on thrust on the proper management of the rooms and its infrastructures. A third party HEI must thrust that the room's HEl owner will correctly manage the room, assuring that any evaluation executed in that room is correctly executed and all the technical issues are correctly handled. The final quality of the evaluation process is dependent of the quality of the management these rooms.

The inter HEl agreements will be rendered into a set of rules and a certification process will be designed, in order to have a standard level of service across all the rooms. Together with the certification process, it will also be defined an audit process in order to regularly verify the compliance of the rooms with the previously designed certification standard.

Currently, the project to create the evaluation rooms is being developed at the University of Porto [7], the University of Minho [8], and the University of Trás-os-Montes and Alto Douro [9].

\section{THE VDI INFRASTRUCTURE}

The advancements in ICT, have provided a set of various solutions for secure desktop environments, which can be categorized as: Desktop as a Services (DTAAS) [10][11]; and Virtual Desktop Infrastructure (VDI) [12][13]. These models differ on the fact that DTAAS is offered by a service provider on the cloud, and VDI is hosted on a premises datacenter. For our solution to implement the rooms' infrastructure, we opted for the VDI model, as one of the requirements was to use the local datacenter.

The DTAAS would offer another advantage, as the IT department wouldn't have to worry about the management of the virtual infrastructure, which would be maintained by a third party service provider, including most of the infrastructure elements, e.g., the network, servers, user desktops, and hosted applications. On the other hand, for the VDI, it is necessary to assemble and maintain the entire infrastructure locally.

Having decided to use the VDI, the evaluation rooms must comply with the structure explained as follows. In each room, there are PCs connected, by wire only, to a local switch, which is connected to a datacenter, where a VDI infrastructure provides the necessary image to boot up each of the clients. A similar infrastructure is implemented in each one of the datacentre of the HEls, so a PC located at UTAD can download an image from a server hosted at UP and boot an Operative System (OS) designed by the UP's staff. This OS will be customized for a group of users that will have an evaluation exam prepared by a professor at UP. The UTAD's staff will have no interaction, other than specifying to the PC which server to connect, providing a secure and trusted relation. There will be also a central management computer, which will monitor all data activities on the PCs of the 
evaluation rooms. Also, to guarantee a minimum risk of fraud, surveillance cameras will be set in place on the evaluation room.

The student, who will attend an evaluation exam, will authenticate himself on the VDI infrastructure, by using his Portuguese citizen card, which has a chip with two digital certificates: one for digitally sign documents; and a second, for secure authentication [14]. Using this card, the digital certificate for authentication purposes, and a card reader connected to the PC, he will be authenticated into the system, and the desktop will load the right profile for him to proceed with the exam. The network connection between the two universities, the VDI provider and the student university of origin, will be made using a Virtual Private Network (VPN) [15], configured with a high security level.

The infrastructure will provide central storage for the PC images, and also private personal storage, linked to the user profile, which will allow mobility between different PCs. The VDI infrastructure will be based on OpenStack technology, an open source cloud operating system, and will provide mobility, centralized resources, and secure data [16].

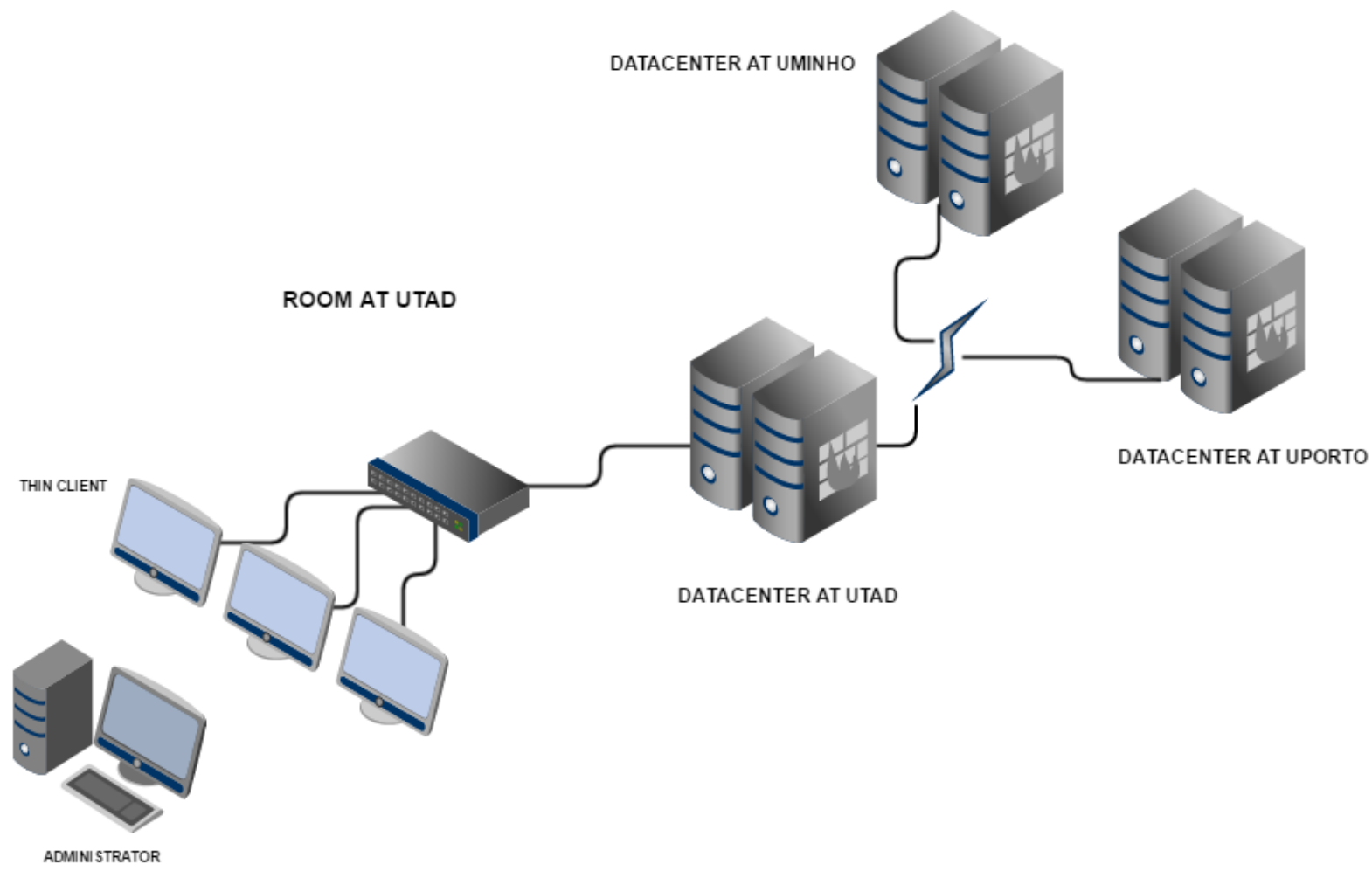

\subsection{Security}

The e-learning exams rooms must warrant the integrity and validity of the evaluation process, addressing the security concerns related to the usage of virtualization technology.

Secure access: to ensure the full integrity of the system, the access to the room must be allowed only to the students that will attend an assessment. The identity of each student must be checked at the entrance of the room, by presenting his citizen card to the staff. The students will also use the citizen card to log in the PC at the evaluation room. The authentication certificate, stored in the citizen card chip, used for authentication, will be matched to a user profile in the authentication of the VDI structure. Students will use the Personal Identification Number (PIN) of the citizen card as the password to log in.

The room will be free of wireless networks, to prevent the access to exterior resources by a portable device. The LAN will also be protected by a firewall, which protects from any non-authorized connection, in or out.

Navigation: The user desktop will have the necessary software to perform the evaluation exam. It can be a browser, in particular the Safe Exam Browser (SEB), which is designed to prevent any kind of fraud, and will open a particular link on the LMS platform or a software, e.g., Autocad, Visual Studio, 
etc. The students will not be allowed to use other software besides the one needed to perform their evaluation and the VDI structure will prevent the connections outside the LAN.

Backup and high availability: VDI and virtualization of the system will provide the necessary tools for high availability, moving the virtual machine, client or server, to other available computer, in one of the HEls' datacenter, in case of hardware failure. Online replication of virtual machine to other HEl's datacenter will also provide a fast recovering option in case of failure. Storage will also be replicated to other HEl's datacenter. Backup will also be implemented, so that in case of total failure, recovery will be possible.

Room availability and surveillance: The space plan of the room is another element to take into account in terms of security. The PCs must have a minimum space from each other and a divider between, so that each participant is prevented from being able to watch the other participant's screen. In addition to that, the room will be monitored through video cameras, which will be controlled through a central PC. Also, all events that occur on the evaluation PCs are monitored and logged through this same central PC.

\subsection{Management}

For good management of the rooms, it is required a lot of care, attention and good management knowledgement. The elements of the teams of the three HEls, involved in this project, must have the ability to schedule and prepare the classrooms for an examination request.

The reservation request of an evaluation room should be made through a webpage form, pointing out the day and hour of when the examination will be carried out, as well as the total number of students. This reservation request must be made, at least 24 hours in advance, so the exam room can be properly prepared. A pre-notice will be sent to the student providing indications about the evaluation schedule and the documents to be presented. As for the exams, they must have an identification number, date and time, as well as the identification of the institution where the evaluations were carried out.

It is the responsibility of the team in each institution to ensure the safety and integrity of the examination room and the system itself. Each team must make the necessary configurations so that the entire evaluation process occurs without problems or difficulties. In the event of problems or breaches, these teams must report and work collaboratively for a quick and efficient resolution of these occurrences.

Access to the evaluation room must be controlled, with restricted access, in which only the students registered for the evaluation and properly identified, will be able to access the room. A single member of each team should monitor the room, using surveillance and monitoring cameras through the central PC.

Administrative support should be provided, for: scheduling exams, re-scheduling, availability checking, and flexible scheduling.

\subsection{Operations}

Characterized as a technology room, with the purpose of evaluation and certification for distance education, some rules were set. The first would be the need for human presence in each evaluation. A team member should carry out the surveillance during the examination process. He is responsible for ensuring the integrity and trustworthiness of the evaluation, identification and validation of the students proposed to evaluation. He must ensure that the system is safe and without malfunctions, report problems or violations that may occur, ensure that people unfamiliar with the evaluation process cannot access the room. It is also the responsibility of this team member to cancel the test of a student which violates the integrity of the evaluation process.

The team member must ensure in advance that the evaluation tests are ready to be delivered by the VDI infrastructure. The teacher, responsible for the evaluation test, with the help of a technician, will guarantee that the whole evaluation process is in compliance, ensuring that all preparation is done and in place so it can be given to the student at the right time.

With regard to the operation of the centrally managed evaluation system, the respective technicians, who administer the evaluation room, must verify that all the users proposed for examination (students) have their citizen card registered into the central user authentication system. In addition to user management, the team member designed to support the whole evaluation must configure and prepare 
the VDI image to be loaded by the terminal as required. This process is done through the management system of VDI, where the technician, properly identified and with permissions of administration access configures all the elements for the accomplishment of evaluation.

At the end of the evaluation, the technician would have to give access of the saved tests to the professor.

He also must verify in the log generated by each PC in the central PC management system if any suspicious action was registered, and produce reports to the management board of the evaluation system.

\section{THE CERTIFICATION}

The three HEls must have strict requirements of security and credibility regarding their evaluation process. Therefore, the exams rooms must have the same architectures in the three universities; the staff must have similar skills to operate the rooms; and there must be mutual thrust. In order to meet these requirements, audits will be carried out, periodically, to verify the compliance of all the evaluations rooms. This audits can be executed by an outsourced service, with the skill to do such tasks, or even by an in house trained team.

The audit will check the items of management, operation and security, previously described. There will be four level of compliance: (1) fully compliant, meaning that hasn't been found a miss compliance, and therefore, the evaluations rooms are fully functional and can be used; (2) substantially compliant, referring a minor miss compliance, which will have to be corrected and are not subject to a new audit; (3) partially compliant, corresponding to a serious miss compliance, which must be corrected within a month, and will be checked again. The non-correction will lead to the closing of the evaluation room; (4) non-compliant, indicating that the room must be immediately shut down, and will remain so, until proper actions are taken. The opening of the evaluation room will be subject a new audit.

\section{CONCLUSIONS AND FUTURE WORK}

The method of evaluation in distance learning is one of the points that causes most inconveniences to the institutions, wishing to certify their distance learning students. Although the entire process of distance learning is practical and advantageous, in some situations, HEls cannot overcome the barrier of the requirement of the physical presence of the student for the evaluation act. Therefore, the creation of evaluations rooms for distance learning is a solution that best address this problem. These rooms, created in the three universities, supported by technology and a controlled environment, will allow the whole process of teaching and learning, through distance learning, to be considered valid and to overcome the difficulties imposed due to mistrusts about the legitimacy of the online assessments. The controlled evaluation space and the high security measures taken in place, in these evaluations rooms for distance learning, allows institutions to be more credible in their evaluation and accreditation processes.

The working teams from the 3 institutions are responsible to define and respect good management practices, including the surveillance of evaluations room's, but also checking the user's identity, as well as the integrity, safety and credibility of whole process. We also concluded that, in regard to this technological challenge, all the involved teams must be prepared and trained in good response, administration management and problem solving. Given that 3 rooms will be interconnected, with a centralized management, the collaboration of the 3 teams is essential and fruitful for the success of this project.

The process of creating an evaluation room for distance learning is very recent, so the motivation and expectations are enormous. For future work we propose three different research lines: 1) evaluation rooms, to find out about the success of the creation of such rooms and its usefulness through monitoring of the room's schedule and occupancy rate of VDI terminals (2) professor and student perception, to known if the evaluation room fulfil the expectations of the professor to use this type of spaces to evaluation activities and to know if the students felted comfortable in this type of room and are satisfied with the online evaluation on certified exams rooms (3) security, to analyze if the security guidelines are suitable to assure the integrity of student knowledge certification. 


\section{ACKNOWLEDGEMENTS}

This work was developed and financed by Project SAMA UNorteX.pt (Project number 022119, Code of Operation POCI-02-0550-FEDER-022119), Programa COMPETE 2020, Portugal 2020.

\section{REFERENCES}

[1] Vicent, L., and M. Segarra. "Learning management system." Multimedia in Education (2010): $21-48$

[2] Ifenthaler, Dirk. "Learning Management System." Encyclopedia of the Sciences of Learning. Springer US, 2012. 1925-1927.

[3] Arsénio Reis, João Barroso, Ramiro Gonçalves: Supporting Accessibility in Higher Education Information Systems. Proceedings of the 7th international conference on Universal Access in Human-Computer Interaction: applications and services for quality of life - Volume Part III; 07/2013, DOI:10.1007/978-3-642-39194-1_29

[4] Luis Barbosa, Paulo Alves, Arsénio Reis, João Barroso: SIDE: Teaching Support Information System. Eunis 2011 Conference - Maintaining a Sustainable Future for IT in Higher Education, Dublin, Ireland; 01/2011

[5] Moodle Pty Ltd. https://docs.moodle.org/32/en/About_Moodle.

[6] Safe Exam Browser. http://safeexambrowser.org/about_overview_en.html.

[7] University of Porto. https://sigarra.up.pt/up/pt/web_base.gera_pagina?p_pagina=u-porto-emsintese.

[8] University of Minho. https://www.uminho.pt/PT/uminho/InformacaoInstitucional/Paginas/default.aspx.

[9] University of Trás-os-Montes e Alto Douro. http://www.utad.pt/vPT/Area2/autad/instituicao/Paginas/default.aspx.

[10] Microsoft Corporation. https://www.microsoft.com/en-us/cloud-platform/desktop-virtualization.

[11] Amazon Webservices. https://aws.amazon.com/workspaces/details/?nc1=h_ls.

[12] Velte, Anthony, and Toby Velte. Microsoft virtualization with Hyper-V. McGraw-Hill, Inc., 2009.

[13] Arsénio Monteiro Reis, J. Borges, F. Rodrigues, J Barroso, A. Costa: A Student Registration System in the Azure Cloud. Eunis 2011 Conference - Maintaining a Sustainable Future for IT in Higher Education, Dublin, Ireland; 01/2011

[14] Arsénio Monteiro Reis, Borges J., Ramiro G., Costa A., João Barroso: PROVIDING UNIVERISTY FEDERATED SERVICES AT UTAD - A PROJECT REPORT. Eunis 2011 Conference - Maintaining a Sustainable Future for IT in Higher Education, Dublin, Ireland; $01 / 2011$

[15] Doraswamy, Naganand, and Dan Harkins. IPSec: the new security standard for the Internet, intranets, and virtual private networks. Prentice Hall Professional, 2003.

[16] Sefraoui, O., Aissaoui, M., \& Eleuldj, M. (2012). OpenStack: toward an open-source solution for cloud computing. International Journal of Computer Applications, 55(3). 